\title{
Temperature Standardization and Quality Standard of Kushta e Gaodanti by Adopting Classical and Modern Methods
}

\author{
Nazeem Fahamiya ${ }^{1,}$, , Shafeek G Ansari ${ }^{2}$, Ansari ZA', Mohammad Aslam³ ${ }^{3}$ Zakir Mohammad ${ }^{4}$, Mohamed Shiffa ${ }^{5}$, \\ Mohammad Zahid Ashraf ${ }^{1, *}$ \\ 'Department of Biotechnology, Faculty of Natural Sciences, Jamia Millia Islamia, New Delhi, INDIA. \\ ${ }^{2}$ Centre for Interdisciplinary Research in Basic Sciences, Jamia Millia Islamia, New Delhi, INDIA. \\ ${ }^{3}$ Department of IImul Advia, School of Unani Medical Education and Research, Jamia Hamdard, New Delhi, INDIA. \\ ${ }^{4}$ Department of IImul Advia, National Research Institute of Unani Medicine for Skin Disorders, Hyderabad, Telangana, INDIA. \\ ${ }^{5}$ Department of Study in Unani, Institute of Indigenous Medicine, University of Colombo, Colombo, SRI LANKA.
}

\begin{abstract}
Background: Kushta Gaodanti (KG) is an essential Unani dosage form prepared by calcination according to classical texts. Standardization is paramount important to check purity and genuineness of the product. However, there are some drawbacks in the calcination process and assessing quality of the drug as per classical method. Hence, this study was aimed to evaluate the quality of KG by classical and modern methods and to develop a quality standard for KG. Methods: A multidisciplinary approach utilizing modern analytical techniques with classical tests was used. Thermogram developed when preparing KG by classical method was used to prepare the drug by Furnace method. The quality of both samples was evaluated on classical parameters like finger test, fineness test, floating test, grain test and wall test and modern physicochemical parameters like bulk density, tapped density, Hausner's ratio, Carr's index, $\mathrm{pH}$, Loss on drying, ash values, and extractive values. Characterization using X-ray diffraction, Scanning Electron Microscopy, Energy Dispersive $X$-ray Analysis, Fourier-Transform Infrared spectroscopy, absorption spectroscopy, Zeta size and potential analysis, and heavy metal analysis have also been carried out to establish the quality standard of KG with modern analytical techniques. Results: The results of the tests done for both the preparations are comparable within experimental error when
\end{abstract}

comparing with each other but non-significant differences were observed in certain parameters. Conclusion: The physicochemical and analytical parameters evaluated in this study may be considered as standard reference for KG. Furthermore, the thermogram developed in this study can be utilized to prepare the Kushta Gaodanti by the furnace method.

Key words: Kushta Gaodanti, Arthralgia, Unani Medicine, Gypsum, Physicochemical.

Correspondence

Prof. Mohammad Zahid Ashraf

Department of Biotechnology, Faculty of Natural Sciences, Srinivasan Ramanujan Block, Jamia Millia Islamia, Jamia Nagar, New Delhi-110025, INDIA.

Email id: zashraf@jmi.ac.in

Dr. Nazeem Fahamiya

Department of Biotechnology, Faculty of Natural Sciences, Srinivasan Ramanujan Block, Jamia Millia Islamia, Jamia Nagar, New Delhi-110025, INDIA.

Email id: nfahamiya@iim.cmb.ac.lk

DOI: 10.5530/jyp.2022.14.13

\section{INTRODUCTION}

Unani drugs are mainly prepared from three different sources such as plant, animal and minerals. The drugs prepared with minerals and metals are considered to be superior when compared with plant and animal origin drugs due to various reasons. It is evident that some metal and mineral preparations have been used by ancient Unani physicians for certain debilitated diseases. In the Unani system of medicine, preparations containing minerals and metals prepared through a specialized calcination process is known as Taklees. The drug obtained through this method is known as Mukallas or Kushta (calcined drug). ${ }^{1}$ In Ayurveda, it is known as Bhasma and Parpams in Siddha. The toxic drugs are converted into safe drugs and the therapeutic efficacy of the drug is enhanced by this calcination process.

Kushta Gaodanti is one of the herbo-mineral drugs prepared with gypsum (Gaodanti) and decoction of Withania somnifera (Asgand) through calcination process which is beneficial in arthralgia, numbness, hemiplegia, facial palsy, gout, fever, cramp, etc. ${ }^{2}$ At present there are many herbo-mineral products available in the market but quality and effectiveness of these products are doubtful because of lack of quality and safety profiles. Preparation of Kustha by classical method is a very laborious and time-consuming procedure. Also, instability in the intensity of the fire, difficulty in controlling temperature and quality of cow dung cakes used to produce heat are some of the issues in the preparation of Kushtajat. These factors lead to fluctuation in the intensity of the heat results in batch-to-batch variation in the quality of the product. In order to overcome these issues modern equipment like furnace, oven and grinding machine could be utilized instead of classical grinding, drying and heating methods of calcination. Previously, the Kusthajat were prepared by the physicians themselves as per their requirements. Nowadays, they are manufactured in large scales in pharmaceutical companies. This new approach will create several problems such as adopting shortcut methods in the preparation, compromising the exact procedures, quality of raw material, etc. Kushtajat are safe when prepared and used in the proper way while prepared in inappropriate and short cut ways, may produce health hazards. Hence, standardization of Kushtajat is compulsory to get the quality product in order to get the desired benefits of the drug.

There are few methods and techniques mentioned in Unani classical texts to ensure the quality of the Kushta but those are highly subjective. Therefore, in this study along with classical tests advanced analytical techniques have been utilized to standardize the Kushta Gaodanti

This is an open access article distributed under the terms of the Creative Commons Attribution-NonCommercial-ShareAlike 4.0 License, which allows others to remix, tweak, and build upon the work non-commercially, as long as the author is credited and the new creations are licensed under the identical terms. 
to confirm its identity, determine its quality, purity and safety for the acceptability of the product.

\section{MATERIALS AND METHODS}

\section{Raw materials}

Gypsum and Withania somnifera were purchased from a local market in New Delhi. Withania somnifera is authenticated by National Institute of Science Communication and Information Resources (NISCAIR), New Delhi. A voucher specimen No. NISCAIR/RHMD/Consult/2018/330708 is submitted in the herbarium of NISCAIR, New Delhi. Gypsum is identified and authenticated by the Department of Chemistry, Jamia Millia Islamia, New Delhi.

\section{Preparation of Kushta Gaodanti}

Kushta Gaodanti was prepared with $100 \mathrm{~g}$ of Gypsum and $100 \mathrm{ml}$ decoction of Withania somnifera by classical method using cow dung cakes and furnace method.

\section{Classical Method of Calcination}

Kushta Gaodanti was prepared as per classical method described in National formulary of Unani medicine. ${ }^{3}$ Gypsum was cleaned with hot water, and triturated in mortar and pestle with decoction prepared with $100 \mathrm{~g}$ of Withania somnifera until it became paste. Pellets were made from paste and dried well at room temperature. Next day, dried pellets were kept inside the two earthen vessels and sealed the mouth of the earthen vessels with mud plaster. A pit with one feet length, width and depth was dug in an open place. $50 \mathrm{~kg}$ of cow dung cakes were used to produce heat. Half the quantity of cow dung cakes was placed at the bottom of the pit. Then, the sealed apparatus (Quza) was placed in the center and the remaining cow dung cakes were kept over it and ignited. At the end of the process of calcination the pit was allowed to cool and the apparatus was removed from the pit. The burned pellets were removed from earthen vessels and made into powder with mortar and pestle. The whole process was repeated two times to prepare the final product. Likewise, three batches of Kushta Gaodanti were prepared and stored in airtight glass bottles. This preparation was termed as KGC. These samples were used to evaluate the quality standard of Kushta Gaodanti.

\section{Temperature Standardization}

A thermogram was developed by recording the temperature changes during calcination with the help of thermocouple digital pyrometer at an interval of $15 \mathrm{~min}$ at the entire course of preparation of Kushta Gaodanti by classical method. The recording of the temperature pattern was repeated three times and the average temperature pattern was utilized to prepare the Kushta by the furnace method.

\section{Furnace Method}

The same formula of Kushta Gaodanti prepared by classical method was used by the furnace method. Purified gypsum is ground with decoction of Withania somnifera in a double stone electrical grinder. Pellets were dried in the oven at low temperature and the dried pellets were kept in a closed crucible. Temperature was set in the tubular furnace as per the thermogram developed with the help of classical method of calcination. The whole process was repeated two times to prepare the final product. Likewise, three batches of Kushta Gaodanti were prepared and stored in airtight glass bottles. This preparation was termed as KGF.

\section{Organoleptic evaluation}

Colour, taste, odour and feel of KGC and KGF were observed.

\section{Classical tests}

The following methods mentioned in the Unani classical texts have been used to test the quality of KGC and KGF such as loss of metallic luster, fineness test, floating test, grain test, smoke test, and wall test. ${ }^{4-6}$

\section{Modern Methods}

Both KGC and KGF were evaluated for physicochemical tests like bulk density, tapped density, Hausner's ratio, Carr's index, $\mathrm{pH}$, loss on drying, total ash, acid insoluble ash, water insoluble ash, water soluble ash and extractive values. ${ }^{6}$

X-ray diffraction (XRD), scanning electron microscopy (SEM), energy dispersive X-ray analysis (EDAX), Fourier-transform infrared spectroscopy (FTIR), spectroscopic analysis and particle size and zeta potential determination have been carried out at central instrumentation facility, Jamia Millia Islamia, New Delhi.

\section{UV-Visible spectroscopy}

Spectroscopic analysis of the samples was carried out with dual beam Hitachi U3900 UV-Vis spectroscopy. $1 \mathrm{ml}$ of aliquot was taken out from the solution and spectroscopic measurement was run at the wavelength of 250 to $650 \mathrm{~nm}^{7}$

\section{X-ray diffraction}

The samples were analyzed by using Ultima IV $\mathrm{X}$ ray diffractometer, with $\mathrm{CuK} \alpha$ radiation $(\lambda=1.541 \AA)$. The acceleration voltage was set at $30 \mathrm{KV}$ and the current flux was set at $40 \mathrm{~mA}$, while the Bragg angle was increased from 20 to 80 degrees.

\section{Scanning Electron Microscopy and Energy Dispersive X-ray Analysis}

The Zeiss EVO ${ }^{\circ}$ MA10 (Carrl Zeiss, Oberkochen, Germany) SEM equipped with energy dispersive system (EDS XMax, $50 \mathrm{~mm}^{2}$ ) controlled by Oxford Instruments Anal System (Oxford Instruments, Oxford, UK) was utilized to study the morphology and elemental composition of samples at a resolution of 1024 x 884 Mag:5000 x HV: $20.0 \mathrm{KV}$.

\section{Fourier-Transform Infrared Spectroscopy}

Bruker's Tensor 37 spectrometer was used for FTIR scanning of samples in attenuated total reflectance (ATR) mode. FTIR was carried out with $5 \mathrm{mg}$ of powder samples with constant nitrogen purging in transmission mode. Average 16 scans in the range of $400-4000 \mathrm{~cm}^{-1}$ at $4 \mathrm{~cm}^{-1}$ resolution had been utilized to take all the spectra.

\section{Particle Size and Zeta Potential Determination}

Samples at the concentration of $1 \mathrm{mg} / \mathrm{ml}$ in distilled water were analyzed for the particle sizes and the zeta potentials by using dynamic light scattering and electrophoretic light scattering with a Zetasizer, Nano ZS (Malvern Instruments Limited, UK) respectively at $25^{\circ} \mathrm{C}$.

\section{Heavy Metal Analysis}

Heavy metal analysis of Gypsum, KGC and KGF samples were done by atomic absorption spectroscopy method according to protocol for testing of AUS medicine.

\section{RESULTS}

A thermogram developed by recording the temperature pattern of Kushta Gaodanti prepared by classical method using cow dung cake is depicted in Figure 1. It was observed that the temperature increased rapidly up to $950^{\circ} \mathrm{C}$ within $2 \frac{1}{2} \mathrm{hr}$ and then decreased steadily over $5 \frac{1}{2} \mathrm{hr}$. Afterwards the temperature remained below $100^{\circ} \mathrm{C}$ for more than $12 \mathrm{hr}$. 


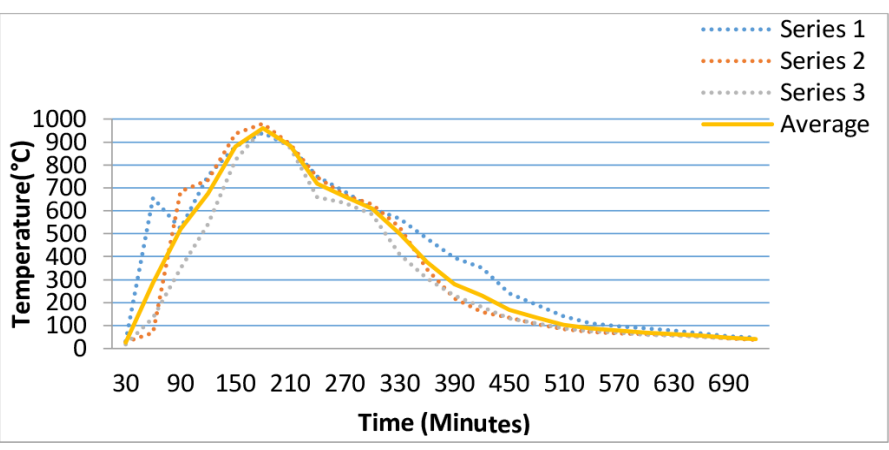

Figure 1: Temperature pattern in the preparation of Kushta Gaodanti by classical method.

Table 1: The results of physico-chemical analysis.

\begin{tabular}{cccc}
\hline \multirow{2}{*}{ S.No } & Parameters & \multicolumn{2}{c}{ Results } \\
\cline { 3 - 4 } A & Kulk Density & $0.87 \mathrm{~g} / \mathrm{ml}$ & $0.91 \mathrm{~g} / \mathrm{ml}$ \\
B & Tapped Density & $1.43 \mathrm{~g} / \mathrm{ml}$ & $1.6 \mathrm{~g} / \mathrm{ml}$ \\
C & Hausner's Ratio (HR) & 1.64 & 1.76 \\
D & Carr's Index & 39.13 & 43.18 \\
E & pH of 1\% solution & 9.91 & 8.71 \\
F & Loss on drying & $0.22 \%$ & $0.21 \%$ \\
G & Ash Value & & \\
a. & Total ash & $99.95 \%$ & $99.96 \%$ \\
b. & Acid insoluble ash & $88.80 \%$ & $87.87 \%$ \\
c. & Water insoluble ash & $98.80 \%$ & $98.025 \%$ \\
d. & Water soluble ash & $1.08 \%$ & $1.925 \%$ \\
H & Extractive value & & \\
a. & Methanolic extract & $0.21 \%$ & $0.17 \%$ \\
b. & Aqueous extract & $1.42 \%$ & $1.24 \%$ \\
\hline
\end{tabular}

The developed thermogram was utilized to prepare Kushta Gaodanti by the furnace method.

The organoleptic evaluation of the both test drugs (KGC and KGF) showed tasteless, odourless, grey in colour and smooth. The results of tests to assure the quality of perfectly prepared Kushta mentioned in the Unani classical text such as loss of metallic luster, fineness test, floating test, grain test, wall test were positive and the smoke test was negative for both samples. The results of physico-chemical tests of samples are summarized in Table 1. The heavy metals analysis showed that Mercury, Arsenic and Cadmium were not detected in all three samples, while Lead was detected in Gypsum (4 ppm), KGC (6.2 ppm), and KGF (6.1 ppm). Results of XRD of gypsum, KGC and KGF are presented in Figure 2. The $2 \theta$ value corresponding to the highest intensity (6272 arb. unit) in gypsum is 11.6 whereas in KGC (2827 arb. unit) and KGF (2646 arb. unit) are 25.46 and 25.42 respectively. The element/molecule for the corresponding $2 \theta$ and intensity of the peaks and their relevant JCPDS files numbers are presented in the Table 2. The absorbance spectra of gypsum, KGC and KGF are depicted in Figure 3 which shows maximum absorption at $228 \mathrm{~nm}$ in the UV region.

FTIR of gypsum, KGC and KGF are illustrated in Figure 4 and functional groups matching with the peaks obtained in FTIR of all the samples are shown in Table 3. The Scanning Electron Microscopy (SEM) was carried

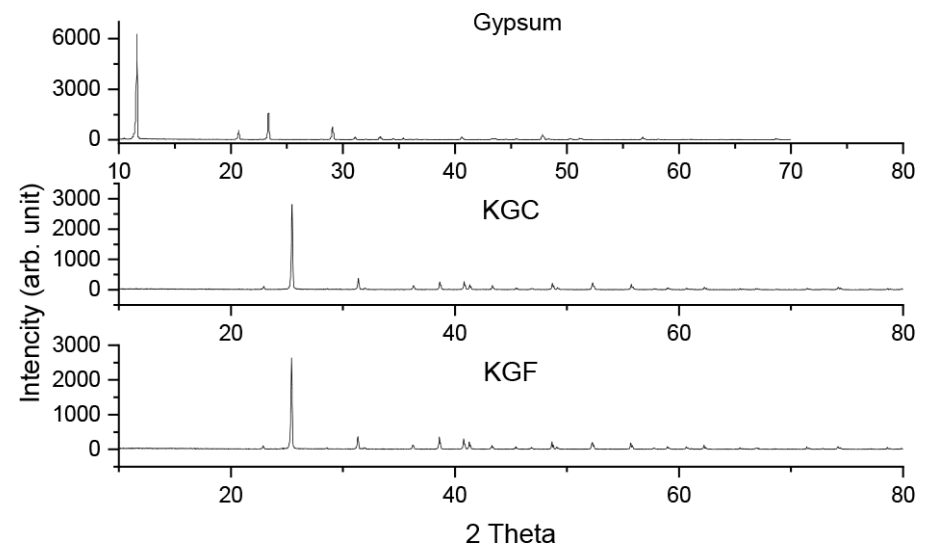

Figure 2: XRD of gypsum, KGC and KGF.

out to analyze the particle size of KGC and KGF. The particle size of KGC ranges from $20 \mathrm{~nm}$ to $7 \mu \mathrm{m}$ while in KGF, it ranges from $40 \mathrm{~nm}$ to $8 \mu \mathrm{m}$ (Figure 5). The EDAX analysis of Gypsum, KGC and KGF revealed that the chief elements are $\mathrm{Ca}, \mathrm{S}, \mathrm{O}, \mathrm{C}$ and their composition in different samples are shown in Table 4 . The Table 5 shows the range of particle size, maximum particles size, average particle size, average zeta potential, zeta deviation, and conductivity of KGC and KGF.

\section{DISCUSSION}

Kushta is an essential dosage form of the Unani system of medicine. It is rapidly absorbed in the human body due to the small particle size and leads to instant therapeutic actions. Though the Kushta Gaodanti is prepared by a specialized process called calcination according to methods mentioned in the classical texts, there are some drawbacks in the procedures. The main issues in the preparation of Kushta by classical method are instability in the intensity of the fire, difficulty in controlling temperature and quality of cow dung cake is not consistent. This can be overcome by utilizing modern equipment like furnace which have effective mechanisms to regulate the temperature. Further, the traditional way of grinding and drying consumes more time than using modern electrical laboratory oven and grinding stone.

In present study, Kushta Gaodanti was prepared by classical method and a thermogram was developed by recording the temperature changes during calcination to prepare the drug by Furnace method. The thermo gram developed in this study can be utilized as a standard temperature pattern to prepare the Kushta Gaodanti by Furnace method. Also, the tests to determine the quality of Kushtajat mentioned in Unani classical texts are highly subjective. Hence, in this study, quality standards of Kustha Gaodanti were developed utilizing classical and modern analytical methods.

Properly prepared Kushta should not have metallic luster and when a pinch of Kushta rubbed between thumb and index finger the powder should enter into finger creases (Fineness test). When sprinkle the Kushta on cold and still water, it should float on the surface (Floating test). Rice grain should not sink when it is placed slowly on floating Kushta if it is the best quality (Grain test). Properly prepared Kushta should not emit smoke when it is burned (Smoke test) and when sprinkled a small amount of Kushta on the wall, finely prepared one will stick to the wall (Wall test). ${ }^{5}$ As per the results the two samples passed the quality tests as stated in the Unani classical texts. The physico-chemical tests such as $\mathrm{pH}$, loss on drying, ash values, and extractive values are comparable within experimental error in all two samples, but some non-significant differences are observed in certain tests like bulk density, tapped density, Hausner's ratio and Carr's index (Table 1). 
Table 2: Molecule and their corresponding JCPDS reference number, $2 \theta$ value and intensity of gypsum, KGC and KGF.

\begin{tabular}{|c|c|c|c|c|}
\hline \multirow{2}{*}{ Molecule } & \multirow{2}{*}{ JCPDS Ref. No } & \multicolumn{3}{|c|}{$2 \theta$ (Intensity) } \\
\hline & & GYPSUM & A & B \\
\hline $\mathrm{CaSO}_{3}\left(\mathrm{H}_{2} \mathrm{O}\right) 0.5$ & $84-0962$ & & $38.66(260)$ & $38.6(360)$ \\
\hline $\mathrm{CaSO}_{4}\left(\mathrm{H}_{2} \mathrm{O}\right) 0.67$ & $85-0531$ & & $41.4(186)$ & \\
\hline $\mathrm{Ca}\left(\mathrm{HSO}_{4}\right) 2$ & $85-1271$ & & $22.9(127)$ & $22.9(115)$ \\
\hline \multirow{5}{*}{$\mathrm{Ca}\left(\mathrm{SO}_{4}\right)\left(\mathrm{D}_{2} \mathrm{O}\right) 2$} & $86-0945$ & $11.6(6272)$ & & \\
\hline & & $20.7(535)$ & & \\
\hline & & $29.1(764)$ & & \\
\hline & $86-0943$ & & $31.38(375)$ & $31.34(381)$ \\
\hline & 86-0945 & & $36.32(144)$ & $36.28(137)$ \\
\hline $\mathrm{CaAl}_{3}\left(\mathrm{PO}_{4}\right)\left(\mathrm{SO}_{4}\right)(\mathrm{OH})_{6}$ & $87-0600$ & & $40.82(270)$ & $40.78(300)$ \\
\hline (Ca. Na, La, Gd)10(P, S)6O24(F, OH)2 & $87-2026$ & & $25.46(2827)$ & $25.42(2646)$ \\
\hline $\mathrm{Ca}\left[\left(\mathrm{H}_{\mathrm{S}} \mathrm{O}_{4}\right) 2\left(\mathrm{H}_{2} \mathrm{O}_{4}\right) 2\right]$ & 88-0764 & & & $41.28(228)$ \\
\hline \multirow[t]{4}{*}{$\mathrm{Na} 6 \mathrm{CaMg}\left(\mathrm{IO}_{3}\right) 6\left(\mathrm{CrO}_{4}\right)_{2}\left(\mathrm{H}_{2} \mathrm{O}\right)_{12}$} & $88-1219$ & $23.4(1586)$ & & \\
\hline & & $31.1(170)$ & & \\
\hline & & $40.6(205)$ & & \\
\hline & & $47.8(311)$ & & \\
\hline $\mathrm{Ca}\left[\mathrm{Zn}_{8}\left(\mathrm{SO}_{4}\right) 2(\mathrm{OH}) 12 \mathrm{C}_{12}\right]\left(\mathrm{H}_{2} \mathrm{O}\right) 9$ & $89-0851$ & $33.3(209)$ & & \\
\hline \multirow[t]{3}{*}{$\mathrm{Ca}\left(\mathrm{SO}_{4}\right)\left(\mathrm{H}_{2} \mathrm{O}\right) 0.662$} & $89-1445$ & & $43.34(144)$ & $43.3(127)$ \\
\hline & & & $52.30(228)$ & $52.28(198)$ \\
\hline & & & & $62.24(127)$ \\
\hline$(\mathrm{Na}, \mathrm{Ca}) 4\left(\mathrm{Al}_{7} \mathrm{Si}\right) 12 \mathrm{O}_{24}\left(\mathrm{Cl}, \mathrm{CO}_{3}, \mathrm{H}, \mathrm{SO}_{4}\right)$ & $89-7419$ & & $55.74(197)$ & \\
\hline \multirow[t]{2}{*}{$\mathrm{Ca} 0.857 \mathrm{Na} 0.285(\mathrm{SO} 4)\left(\mathrm{H}_{2} \mathrm{O}\right) 0.473$} & $89-8618$ & $56.8(170)$ & & \\
\hline & $89-8619$ & & $48.68(218)$ & $48.66(218)$ \\
\hline $\mathrm{Ca}\left[\left(\mathrm{NH}_{2}\right) \mathrm{SO}_{3}\right] 2\left(\mathrm{H}_{2} \mathrm{O}\right) 4$ & $89-9106$ & & & $55.68(198)$ \\
\hline
\end{tabular}

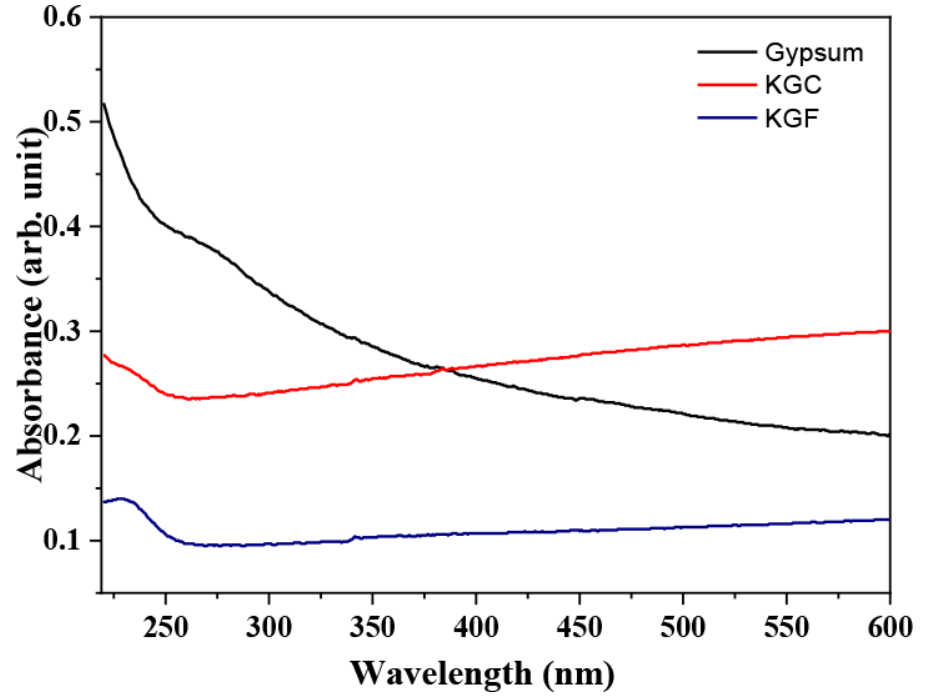

Figure 3: Absorbance spectra of gypsum, KGC and KGF.

The results of heavy metal analysis of Gypsum, KGC and KGF are found to be within the permissible limits as per the World Health Organization (WHO) permissible limits for heavy metals.

When comparing the molecules in the gypsum and the Kushta Gaodanti prepared by classical and furnace methods, new molecules are identified

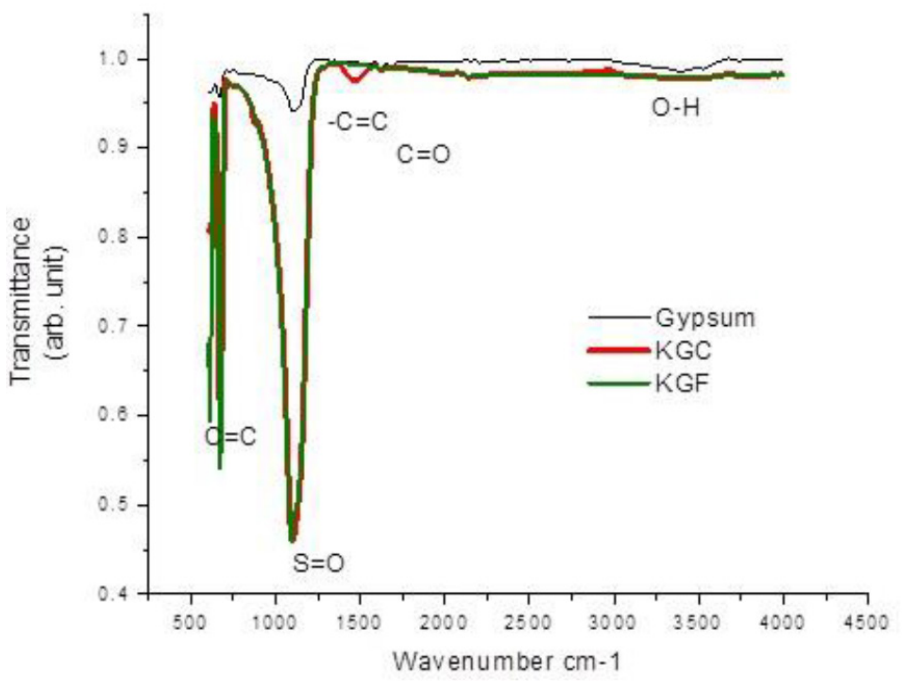

Figure 4: FTIR of gypsum, KGC and KGF.

in the KGC and KGF. Further, almost similar compounds are present in the KGC and KGF (Table 2). Different molecules absorb radiation of different wavelengths in UV-Visible absorption spectroscopy in the ultraviolet-visible spectral region (UV range $150-400 \mathrm{~nm}$ and visible range $400-800 \mathrm{~nm}){ }^{8}$ The absorption spectrum produced by this shows the absorption bands corresponding to the structural groups present in 
Fahamiya, et al.: Synthesis, Characterisation and Cytotoxic Studies of Novel Curcumin-Metformin Conjugate

Table 3: Functional groups of gypsum, KGC and KGF.

\begin{tabular}{|c|c|c|c|c|}
\hline \multirow[b]{2}{*}{ S.No. } & \multirow[b]{2}{*}{ Functional group } & \multicolumn{3}{|c|}{ Peak } \\
\hline & & Gypsum & $\begin{array}{c}\text { Sample } \\
\text { A }\end{array}$ & $\begin{array}{l}\text { Sample } \\
\text { B }\end{array}$ \\
\hline 1 & Strong $\mathrm{C}=\mathrm{C}$ bending alkene & 665.3907 & 675.074 & 675.84 \\
\hline 2 & $\begin{array}{c}\text { Medium } \mathrm{C}=\mathrm{C} \text { bending alkene } \\
\text { trisubstituted }\end{array}$ & 796.59 & & \\
\hline 3 & $\begin{array}{c}\text { Strong } \mathrm{S}=\mathrm{O} \text { stretching sulfonic } \\
\text { acid }\end{array}$ & 1100.67 & 1098.86 & 1098.86 \\
\hline 4 & $\mathrm{C}-\mathrm{H}$ bend alkanes & & 1460.08 & \\
\hline 5 & $\begin{array}{l}\text { Strong } \mathrm{N}-\mathrm{O} \text { stretching nitro } \\
\text { compound }\end{array}$ & 1537.64 & & \\
\hline 6 & $\begin{array}{c}\text { Medium } \mathrm{C}=\mathrm{C} \text { stretching cyclic } \\
\text { alkene }\end{array}$ & 1625.86 & & \\
\hline 7 & $\begin{array}{l}\text { Strong } \mathrm{C}=\mathrm{O} \text { stretching } \\
\text { conjugated acid dimer }\end{array}$ & 1684.91 & & \\
\hline 8 & $\begin{array}{c}\text { Weak } C \Xi C \text { stretching alkyne } \\
\text { disubstituted }\end{array}$ & 2204.46 & & \\
\hline 9 & Medium CH stretching & & & \\
\hline 10 & $\begin{array}{l}\text { Strong broad O-H stretching } \\
\text { alcohol inter molecular bonded }\end{array}$ & 3390.31 & & \\
\hline 11 & $\begin{array}{l}\text { Strong broad O-H stretching } \\
\text { alcohol inter molecular bonded }\end{array}$ & 3525.76 & & \\
\hline
\end{tabular}

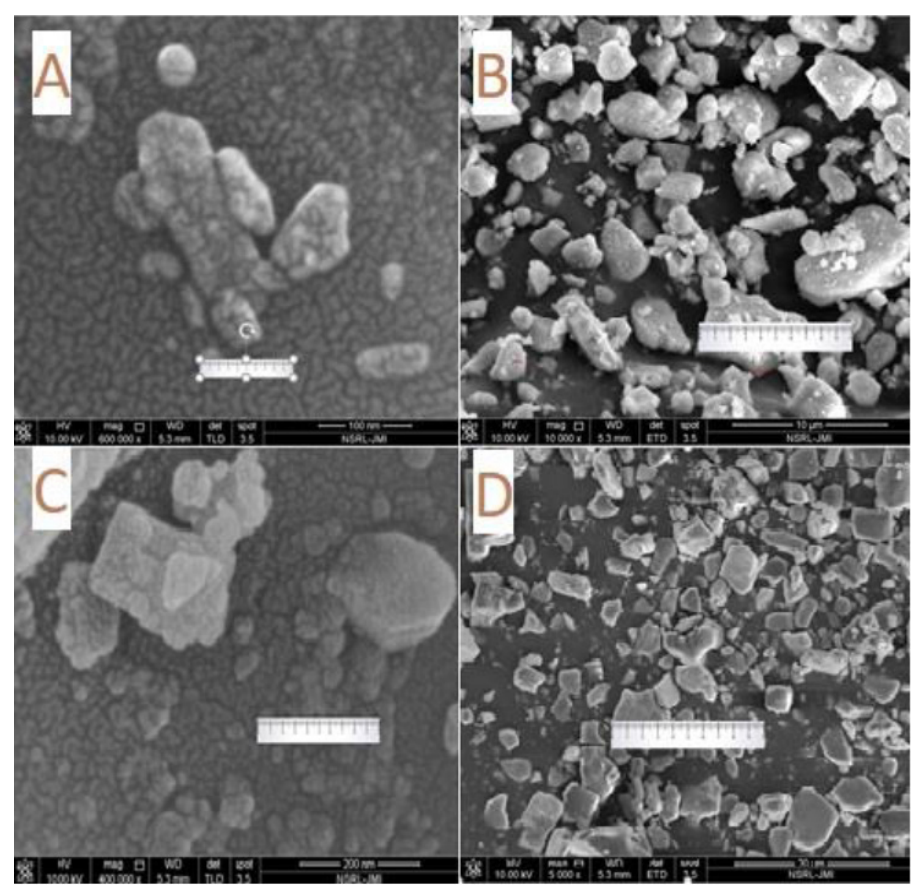

Figure 5: Scanning Electron Microscopy. (A) KGC (X 600,000); (B) KGC (X 10,000); (C) KGF (X 600,000); (D) KGF (X 10,000).

the molecule. Though, there are differences in the absorbance spectra of gypsum, KGC and KGF (Figure 3), the maximum absorption value is same for all three samples (228 $\mathrm{nm}$ in the UV region).

Energy transfer takes place in the manner of electron ring shift, molecular bond vibrations, rotations and stretching of bonds. The principle of FTIR
Table 4: EDAX analysis of Gypsum, KGC and KGF.

\begin{tabular}{cccc} 
Elements & $\begin{array}{c}\text { Gypsum } \\
\text { C Atom. [at.\%] }\end{array}$ & $\begin{array}{c}\text { KGC } \\
\text { C Atom. [at.\%] }\end{array}$ & $\begin{array}{c}\text { KGF } \\
\text { C Atom. [at.\%] }\end{array}$ \\
\hline O & 3.0 & 61.58 & 61.88 \\
$\mathrm{Ca}$ & 23.31 & 13.63 & 14.23 \\
$\mathrm{C}$ & 3.8 & 12.66 & 12.70 \\
$\mathrm{~S}$ & 18.15 & 12.13 & 11.19 \\
\hline
\end{tabular}

Table 5: Zeta size and potential values of KGC and KGF.

\begin{tabular}{|c|c|c|c|c|c|c|}
\hline $\begin{array}{l}\frac{0}{0} \\
\text { है } \\
\text { N }\end{array}$ & 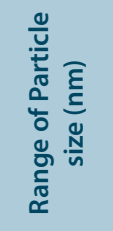 & 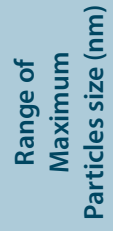 & 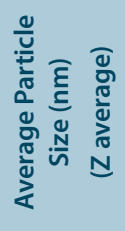 & 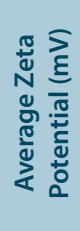 & 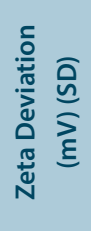 & 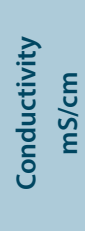 \\
\hline KGC & $\leq 1-8555$ & $\begin{array}{c}395.67 \pm \\
53.50\end{array}$ & 1298 & -8.95 & 1.54 & 0.0212 \\
\hline KGF & $\leq 1-8600$ & $\begin{array}{c}542.6 \pm \\
125.05\end{array}$ & 1827 & -6.00 & 0.34 & 0.0218 \\
\hline
\end{tabular}

is based on the molecular movement to higher states by absorbing the light in the IR range. FTIR spectra of a sample is analyzed as a function of wavelength or wavenumber of incident radiation. The FTIR spectra gives valuable information about the structure of the particular molecules via appearance and nonappearance of certain vibrational frequencies. As each functional group has unique vibrational frequencies the FTIR spectra also gives the information on the existence of certain functional groups in the sample for their characterizations. ${ }^{9}$

According to the FTIR spectrum it can be assumed that presence of functional group $\mathrm{S}=\mathrm{O}$ (strong) is more prominent in KGC and KGF than gypsum while new functional group $\mathrm{C}-\mathrm{H}$ bend has been formed in KGC and the $\mathrm{O}-\mathrm{H}$ which was present in the gypsum is completely disappeared in both the Kushtajat (KGC and KGF).

As seen in Figure 5, particles are heterogeneous and in nano size. Therefore, these drugs have increased rate of absorption and quick effects on the tissues. The EDAX analysis of Gypsum, KGC and KGF revealed that the chief elements are $\mathrm{Ca}, \mathrm{S}, \mathrm{O}$, and $\mathrm{C}$. The percentage of Calcium (23.31\%) and Sulphur (18.15\%) were greater in raw Gypsum than in two Kushta e Gaodanti preparations. The Calcium and Sulphur in KGC are $13.63 \%$ and $12.13 \%$ while in KGF $14.23 \%$ and $11.19 \%$ respectively. The highest element is $\mathrm{O}$ in Kushta Gaodanti that is $61.58 \%$ in KGA and $61.88 \%$ in KGF. The percentage of $\mathrm{C}$ element is very low in raw gypsum (3.8 \%) and it was increased to $12.66 \%$ and $12.70 \%$ in KGA and KGF respectively.

The particle size of the drug is a key factor in determining its therapeutic efficacy in the body by rapid absorption and dispersion. The range of maximum particle size of KGC and KGF are $395.67 \pm 53.50 \mathrm{~nm}$ and $542.6 \pm 125.05 \mathrm{~nm}$ respectively. This shows that the procedures carried out during the calcination process are responsible for the reduction of the size of particles. Further, nano size of the samples is reason for quick absorption and enhance therapeutic efficacy in the body. Zeta potential is an electrical potential between particles to identify the colloidal stability of the substance. Substances with high zeta potential are having good stability and easy dispersion while substances with low zeta potential are vice versa. ${ }^{9}$ The Zeta Potential (mean) value of KGC (-8.95 mV) and KGF $(-6.00 \mathrm{mV})$ are found to be very low which indicate aggregation and less stability of particles in the suspension. Furthermore, KGC is more stable than KGF. 


\section{CONCLUSION}

This study reveals multidisciplinary approach utilizing modern analytical techniques with classical tests would be more suitable in assessing the quality of Kushtajat. The results of physicochemical tests of Kushta Gaodanti prepared by classical cow dung cake method and modern furnace method are comparable within experimental error when comparing with each other but non-significant differences were observed in XRD, SEM, EDAX, FTIR, UV absorption spectroscopy, Zeta size and potential analysis. Therefore, by using advanced analytical techniques this work grants an applicable correlation between the traditional information on characterization and processing of Kustha. Further, the physicochemical and analytical parameters evaluated in this study may be considered as standard reference for Kushta Gaodanti to give safe and effective medication for mankind.

\section{ACKNOWLEDGEMENT}

The authors are thankful to the University Grants Commission, Sri Lanka, the Central Council of Research in Unani Medicine, New Delhi, Jamia Millia Islamia, New Delhi, National Research Institute of Unani Medicine for Skin Disorders, Hyderabad, and Jamia Hamdard, New Delhi for providing financial, laboratory and other facilities.

\section{CONFLICT OF INTEREST}

The authors declare that there is no conflict of interest.

\section{ABBREVIATIONS}

KGC: Kushta Gaodanti was prepared by classical method; KGF: Kushta Gaodanti prepared by furnace method; XRD: X-ray diffraction; SEM: scanning electron microscopy; EDAX: energy dispersive X-ray analysis; FTIR: Fourier-transform infrared spectroscopy.

\section{REFERENCES}

1. Qasmi IA. Kitab UI Taklees. Aligarh: Aligarh Muslim University; YNM.

2. Sana'tulTaklees HA. New Delhi: Central Council for research in Una ni Medicine, Ministry of Health and Family Welfare, government of India: YNM.

3. Anonymous. National formulary of Una ni Medicine. Part 1. New Delhi: Department of AYUSH, Government of India, Ministry of Health and Family Welfare; 2006.

4. Tariq M, Chaudhary SS, Zaman R, Rahman K, Imtiyaz S, Tariq M, et al. Physicochemical standardization of Kushta abrak Safaid: A Herbo-mineral Una ni formulation. Int J Pharm Sci Drug Res. 2013;5(3):129-32.

5. Kabeeruddin HM, Taklees KAl, Central Council for Research in Unani Medicine. New Delhi: YNM.

6. Ali MA, Hamiduddin $H$ H, Zaigham M, Nafees S, Ikram M, Jahangeer G. Comparative physicochemical analysis of Kushta-E-Murdarsang prepared by classical and muffle furness method. J Young Pharm. 2021;13(3):205-10. doi: 10.5530/jyp.2021.13.43

7. Schmid F-X. Biological macromolecules: UV-visible spectrophotometry. Germany: Macmillan publishers Ltd. Nature Publishing Group, University of Bayreuth; 2001. doi: 10.1038/npg.els.0003142.

8. Bajpai DN. Advanced physical chemistry. India: S Chand and Company limited; 2015

9. Rugmini RK, Sridurga CH, Venkata Subbaiah K. Analytical study of Tamra Bhasma, International Ayurvedic. Med J. 2018;6(9):1931-41.

Article History: Received:18-11-2021; Revised: 09-12-2021; Accepted: 21-12-2021

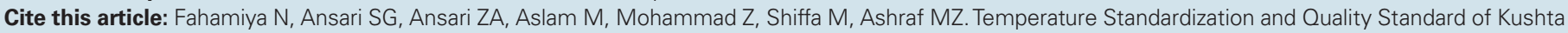
e Gaodanti by Adopting Classical and Modern Methods. J Young Pharm. 2022;14(1):67-72. 